\begin{tabular}{|cc|}
\hline SCOTS PINE & PLANTATION \\
NEEDLES & FOREST FLOOR \\
SUMMER & NIGHT AIR \\
$\alpha$ - PINENE & 3- CARENE \\
SAMPLING & ANALYSIS \\
\hline
\end{tabular}

Open access original manuscript version of Atmospheric Environment 22 (1988) 2617-2619

Link to publisher: doi:10.1016/0004-6981(88)90497-0

\title{
High ambient concentrations of monoterpenes in a Scandinavian pine forest
}

\author{
Göran Petersson \\ Subsequent studies of terpene emissions were made for: \\ Logging in conifer forests \\ Barking of logs and pulpwood \\ $\underline{\text { Kraft pulp mills }}$
}


HIGH AMBIENT CONCENTRATIONS OF MONOTERPENES IN

SCANDINAVIAN PINE FORESTS

\author{
Göran Petersson \\ Department of Chemical Environmental Science, \\ Chalmers University of Technology, s-412 96 Göteborg, Sweden
}

Abstract - Total monoterpene levels of the order of $100 \mu \mathrm{g} / \mathrm{m}^{3}$ were assessed in the summer-night air of a typical young planted forest of scots pine (Pinus silvestris) in sweden. High emissions, the choice of time and place, and analytical progress may explain the observed, very high concentrations, compared to those reported in previous studies of ambient monoterpenes. Predominant species were $\alpha$-pinene and 3 -carene. Camphene, $\beta$-pinene, myrcene, $\beta$-phellandrene and limonene were other prominent components determined. The monoterpenes were shown to originate almost exclusively from scots pine and the proportions between them to be characteristic of this conifer species. Implications for the involvement of the terpenes in atmospheric chemistry and photooxidant formation are discussed.

Key word index: Terpenes, $\alpha$-pinene, 3-carene, biogenic hydrocarbons, ozone, Scots pine, Pinus silvestris, forest canopy, summer night, Sweden. 
INTRODUCTION

Wide-spread forest decline in Europe was first attributed mainly to effects of soil acidification. Only recently, direct effects of ozone and other oxidants have been emphasized as a major explanation (Ashmore et al., 1985). Accordingly the role of terpenes in the formation of oxidants is currently a matter of great interest. The measurements reported here were made just before the general recognition, in 1984, of forest decline in certain areas in southern Sweden.

Because of their reactivity, the determination of monoterpenes in ambient air is more difficult than the corresponding determination of anthropogenic hydrocarbons. Early studies were limited to $\alpha$-pinene, the major monoterpene in most conifer forests, and in some cases $\beta$-pinene, 3-carene and limonene (Altshuller, 1983). Apparently, methodological shortcomings explain some of the discrepancies observed between low reported ambient levels and high biogenic emissions of monoterpenes. An important object of this study was the choice of methods and conditions permitting true near-maximum ambient levels to be determined for all prominent monoterpenes.

\section{EXPERIMENTAL}

Sampling site. A forested region west of the town Jönköping in south central Sweden was chosen for this study. The whole area is almost flat and further to the west is a large peat-bog. The site of sampling was located $3 \mathrm{~km}$ north-west of Jönköping Airport, from which meteorological data are available. The site is also within $1 \mathrm{~km}$ north of the main road between Jönköping and Göteborg.

Samples were taken inside a plantation of scots pine (pinus silvestris) extending more the $100 \mathrm{~m}$ in all directions. The plantation was of the kind normally used in Swedish forestry for poor soils. Norwegian spruce (Picea abies) occurs in the area, but near the sampling site 10-15 year-old pines were the only trees 
present. Prominent field species were Calluna vulgaris and Vaccinium vitis-idaea. Typical cryptogams were the moss Dicranum undulatum and the lichen Cladonia rangiferina. Pine needles were a major component of the litter. Air samples were taken just a few $\mathrm{cm}$ above ground, unattended over night.

Meteorological data. The following data from Jönköping Airport refer to the two summer nights in 1983 when the samples accounted for in this study were taken.

June $20,19.00: 22^{\circ} \mathrm{C}, 40 \%$ (relative humidity), $1 / 8$ (cloudiness), $3 \mathrm{~m} / \mathrm{s} \mathrm{NE}$ (wind).

June $21,01.00: 10^{\circ} \mathrm{C}, 95 \%, 1 / 8,2 \mathrm{~m} / \mathrm{s} \mathrm{s}$

$07.00: 16^{\circ} \mathrm{C}, 59 \%, 7 / 8,6 \mathrm{~m} / \mathrm{s} \mathrm{ENE}$

July $08,19.00: 26^{\circ} \mathrm{C}, 358,3 / 8,4 \mathrm{~m} / \mathrm{s} \mathrm{NNE}$

July 09, 01.00: $14^{\circ} \mathrm{C}, 90 \%, 3 / 8,0 \mathrm{~m} / \mathrm{s}$

$07.00: 19^{\circ} \mathrm{C}, 798,6 / 8,2 \mathrm{~m} / \mathrm{s} \mathrm{W}$

Sampling and analysis. The methods used for sampling and analysis were very similar to those previously applied in analysis of trace anthropogenic hydrocarbons in air (Mattsson and Petersson 1982). Therefore, only a few essential features and modifications are mentioned here.

Tenax GC packed into glass liners was used for adsorption. Portable sampling pumps provided the air flows of choice. The adsorbent tubes were protected against light and contamination during sampling and transport to the laboratory.

Thermal desorption was effected directly from the injector onto the cooled column in a Carlo-Erba gas chromatograph. The column was a $25 \mathrm{~m} \mathrm{x} 0.33 \mathrm{~mm}$ ID fused silica capillary, covered with a $0.5 \mu \mathrm{m}$ thick layer of cross-linked methyl silicone as the stationary phase (SGE 25 QC3/BP1-0.5). Temperature was increased $2^{\circ} \mathrm{C} / \mathrm{min}$ linearly from $0^{\circ} \mathrm{C}$, and detection was by flame ionization coupled to a reporting integrator. Response was determined for $\underline{n}$-heptane by two independent methods and the same response factor was used for all terpenes. 
The monoterpenes were identified by comparison of relative retentions for different stationary phases and by comparison with authentic samples.

\section{RESULTS AND DISCUSSION}

Results are given in Table 1, from four samples taken at the sampling site during two nights of the summer 1983. The gas chromatogram reproduced in Fig. 1 shows the monoterpene section of the fourth sample. Duplicate samples using different air volumes and adsorption tubes were found to be useful in controlling recovery of reactive monoterpenes as well as artifacts and analytical performance.

Terpenes from pine. The sampling site inside a young planted forest of scots pine was chosen so as to minimize influence from other tree species. Comparisons with samples from different forest stands were made to confirm that the terpenes originated from pine. Norwegian spruce (Picea abies) is the only other major conifer in the region. It was found to give rise to a very different composition of monoterpenes with much higher proportions of camphene and limonene and low levels of 3-carene. Significant contributions attributed to pine were found in pure stands of spruce during the night. This indicates transport of monoterpenes by air and higher emissions from pine than from spruce. Pine stands with a different composition of field plants exhibited a pattern of monoterpenes very similar to that reported, although all samples were taken near the ground. Evidently, plants other than conifers contributed little to the monoterpenes in the air. It is concluded that the composition of monoterpenes reported is characteristic of Pinus silvestris in the scandinavian summer season. 
Table 1. Concentration levels $\left(\mu \mathrm{g} / \mathrm{m}^{3}\right)$ of major monoterpenes ${ }^{*}$ in a Swedish pine forest during two summer-nights.

\begin{tabular}{|c|c|c|c|c|}
\hline \multirow{3}{*}{$\begin{array}{l}\text { Date } \\
\text { Time } \\
\text { Air sample }\end{array}$} & \multicolumn{2}{|c|}{$6 / 20-21 / 1983$} & \multicolumn{2}{|c|}{$7 / 8-9 / 1983$} \\
\hline & \multicolumn{2}{|c|}{$21.45-08.30$} & \multicolumn{2}{|c|}{$21.45-08.15$} \\
\hline & 1.041 & 4.331 & 0.791 & 3.811 \\
\hline$\alpha$-pinene & 54 & 49 & 23 & 28 \\
\hline camphene & 3.9 & 1.4 & 2.7 & 1.9 \\
\hline$\beta$-pinene & 1.8 & 1.6 & 1.4 & 2.5 \\
\hline myrcene & 1.2 & 0.8 & 1.4 & 1.1 \\
\hline 3-carene & 39 & 35 & 27 & 30 \\
\hline$\beta$-phellandrene & 2.2 & 1.5 & 1.5 & 1.6 \\
\hline limonene & 7.3 & 5.5 & 1.9 & 1.3 \\
\hline
\end{tabular}

* Concentrations of $\alpha$-thujene, sabinene, $\alpha$-phellandrene, $\gamma$-terpinene, terpinolene and $\mathrm{p}$-cymene were below $1 \mu \mathrm{g} / \mathrm{m}^{3}$. 


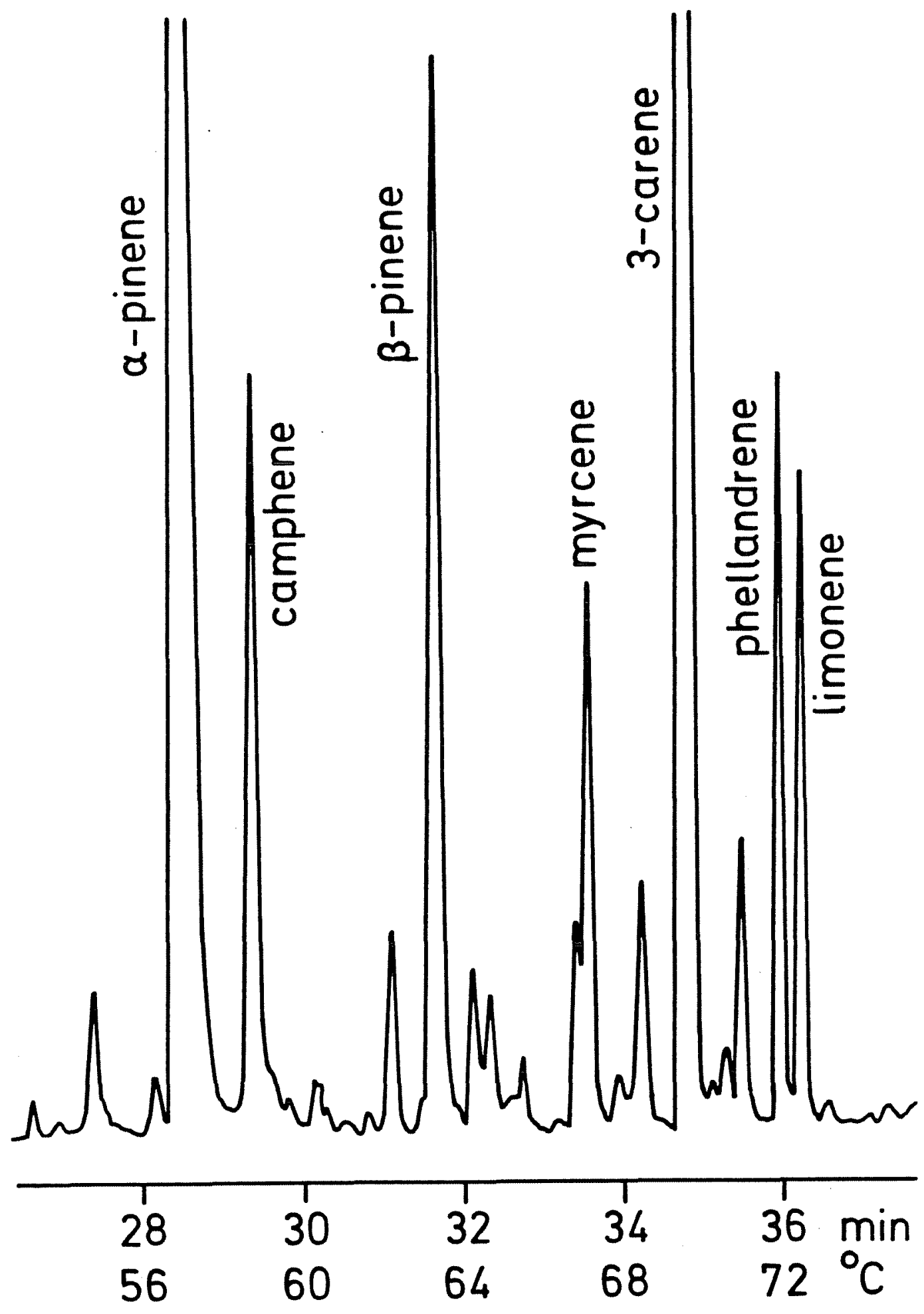

Legend to Figure 1

Gas chromatographic separation of monoterpenes from the night-time air of a Swedish plantation of Scots pine. 
As shown in Table 1 , the two species $\alpha$-pinene and 3 -carene predominate and account for more than $80 \%$ of the total monoterpenes. In France, $\alpha$-pinene and $\beta$-pinene were demonstrated to be the major monoterpenes from another European pine species, Pinus pinaster (Riba et al., 1987). In a Japanese planted forest of Pinus densiflora, $\alpha$-pinene was the major component (Yokouchi et al., 1983). Camphene, $\beta$-pinene, myrcene and $\beta$-phellandrene were also recorded. 3-Carene, originating from pine species, occurs as one of the prominent monoterpene components in the air of mixed conifer forests in the United States (Holdren et al., 1979; Roberts et al., 1983) as well as the Soviet Union (Isidorov et al., 1985). It is evident that the monoterpene characteristics of Pinus silvestris, as given in Table 1, differ markedly from those of other pine species because of large differences in composition as well as emission rates. Differences in composition within the species between various provenances, localities and times of the day and year may exist as well, but are likely to be much smaller.

It is important to note that monoterpene emissions from needles and other parts of the tree differ in composition and that emissions from stem and branches may be considerable for pine species. Studies of emissions from twigs, i.e. mainly needles, by enclosure techniques have demonstrated $\alpha$-pinene, $\beta$-pinene and limonene to be major monoterpene components from Pinus silvestris (Ciccioli et al., 1984; Isidorov et al., 1985). 3-Carene was not a prominent component. On the other hand, 3-carene and $\alpha$-pinene are known to be major monoterpenes from wood of scots pine. As a consequence the composition of monoterpenes in ambient air cannot easily be deduced by enclosure techniques even if contributions from other species than scots pine are negligible. 
Concentration levels. With respect to ecological considerations as well as impact on atmospheric chemistry, the occurrence of high concentrations of monoterpenes is of particular interest. From Table 1 it is evident that the total concentration of monoterpenes at the sampling site may exceed $100 \mu \mathrm{g} / \mathrm{m}^{3}$. This is at least an order of magnitude higher than reported in most other studies (Altshuller, 1983). An extensive study of nighttime monoterpene concentrations in Colorado, USA (Roberts et al., 1985) reported maximum total summer levels to be about $5 \mu \mathrm{g} / \mathrm{m}^{3}$. Among the very few reported comparatively high concentration levels is approximately $40 \mu \mathrm{g} / \mathrm{m}^{3}$ during the night in a French forest of Pinus pinaster (Riba et al., 1987). Similar maximum levels were found near needles and stem in a Norwegian forest of Picea abies (Hov et al., 1983). Surprisingly, p-cymene and $\gamma$-terpinene were stated to be among the prominent components in the latter study.

The deliberate choice of sampling conditions favouring high ambient concentrations is thought to be a major explanation for the high levels recorded. On both sampling occasions weather with sunny, hot $\left(20-30^{\circ} \mathrm{C}\right)$ days and $\operatorname{cool}\left(10-15^{\circ} \mathrm{C}\right)$, calm, and moist nights prevailed. Monoterpene emissions increase rapidly with temperature leading to maximum concentrations in the summer (Altshuller, 1983). Restricted vertical mixing often causes considerably higher concentrations at night than during the day in spite of the lower temperature (Yokouchi et al., 1983; Riba et al., 1987). The flat topography of the area studied prevents air flows of the mountain-wind type and permits a build-up of high monoterpene concentrations within the fairly dense plantation of pines.

It is emphasized that the conditions chosen for the samples reported are by no means exceptional. Similar ambient levels should therefore be found in forests of scots pine every summer during periods of favourable weather. Emission rates from twigs of Scots pine do not appear to be remarkably higher than from several other conifer species (Isidorov et al., 1983). Consequently the levels of ambient monoterpenes recorded are likely to occur in coniferous forests of other high-emitting species as well. 
Atmospheric chemistry. The role of terpenes in the formation of ozone and other oxidants has been debated for a long time. In many regions monoterpenes are considered unimportant because of reported low concentrations compared to anthropogenic hydrocarbons (Altshuller, 1983). The present study demonstrates that this argument is not valid in southern Scandinavia. The concentrations of total alkylbenzenes were only $3.2,2.5,2.8$ and $3.0 \mu \mathrm{g} / \mathrm{m}^{3}$ for the samples in Table 1. Thus the alkylbenzenes, which are a major group of reactive anthropogenic hydrocarbons, were present in concentrations less than $5 \%$ of those of monoterpenes, although the sampling site was not far from traffic emissions. Toluene was the major alkylbenzene and other prominent components were ethylbenzene, the xylenes, the ethylmethylbenzenes and the trimethylbenzenes as expected from previous applications of the analytical technique to anthropogenic hydrocarbons (Mattsson and Petersson, 1982).

The results imply that the total concentrations of monoterpenes inside the forest canopy are of the same order of magnitude as the concentrations of photochemically reactive hydrocarbons in urban areas. As mixing height and winds increase in the morning, extensive "forest plumes" of terpenes are likely to behave similarly to urban plumes of anthropogenic hydrocarbons. Monoterpenes are depleted much faster, however, because of a more rapid chemical degradation in daytime air. Reaction occurs with both ozone and the hydroxyl radical, and the lifetimes of different monoterpenes vary considerably with respect to both types of reactions (Atkinsson et al., 1986). Therefore, knowledge of monoterpene composition is essential for the understanding of atmospheric chemistry. $\alpha$-Pinene and 3-carene have lifetimes of the order of a few hours. Limonene and particularly myrcene disappear much faster outside the forest canopy because of shorter lifetimes, especially with respect to ozonolysis. The time scale for the impact of monoterpenes on the formation of oxidants should be similarly different between the monoterpene species. 
In remote regions, formation of photo-oxidants is hampered by low $\mathrm{NO}_{\mathrm{x}}$ levels. For urban, industrial and traffic plumes with elevated $\mathrm{NO}_{\mathrm{x}}$ concentrations and $\mathrm{CH}_{\mathrm{x}}$-limited photo-oxidant formation, model calculations indicate that terpenes give rise to increased ozone levels (Lurmann et al., 1983). The ozone-forming potential of the pine forests studied is likely to be particularly large. Possibly this will necessitate especially farreaching reductions of anthropogenic emissions in certain areas to compensate for the contributions from terpenes. 
Altshuller A.P. (1983) Review: Natural volatile organic substances and their effect on air quality in the United states. Atmospheric Environment 17, 2131-2165.

Atkinson R., Aschmann S.M. and Pitts J.N.Jr. (1986) Rate constants for the gas-phase reactions of the $\mathrm{OH}$ radical with a series of monoterpenes at $294^{\circ} \mathrm{K}$. Int. J. Chem. Kinet. 18 , 287-299.

Ashmore M., Bell N. and Rutter J. (1985) The role of ozone in forest damage in West Germany. Ambio 14, 81-87.

Ciccioli P., Brancaleoni E., Possanzini M., Brachetti A. and Di Palo C. (1984) Sampling and determination of natural and anthropogenic hydrocarbons in air by GC-MS. Sci. Total Envir. 36, 255-260.

Holdren M.W., Westberg H.H. and Zimmerman P.R. (1979) Analysis of monoterpene hydrocarbons in rural atmospheres. J. Geophys. Res. 84, 5083-5088.

Yokouchi Y., Okaniwa M., Ambe Y. and Fuwa K. (1983) Seasonal variation of monoterpenes in the atmosphere of a pine forest. Atmospheric Environment 17, 743-750.

Hof $\varnothing .$, Schjoldager J. and Wathne B.M. (1983) Measurement and modeling of the concentrations of terpenes in coniferous forest air. J. Geophys. Res. 88, 10679-10688.

Isidorov V.A., Zenkevich I.G. and Ioffe B.V. (1985) Volatile organic compounds in the atmosphere of forests. Atmospheric Environment 19, 1-8. 
Lurmann F.W., Lloyd A. and Nitta B. (1983) Modeling potential ozone impacts from natural hydrocarbons - II. Hypothetical biogenic HC emission scenario modeling. Atmospheric Environment 17, 1951-1963.

Mattsson M. and Petersson G. (1982) Trace analysis of hydrocarbons in air using standard gas chromatographic and personal sampling equipment. Intern. J. Environ. Anal. Chem. 11, 211-219.

Riba M.L., Tathy J.P., Tsiropoulos N., Monsarrat B. and Torres L. (1987) Diurnal variation in the concentration of $a$ - and $\beta$-pinene in the Landes Forest (France). Atmospheric Environment 21, 191-193.

Roberts J.M., Fehsenfeld F.C., Albritton D.L. and Sievers R.E. (1983) Measurement of monoterpene hydrocarbons at Niwot Ridge, Colorado. J. Geophys. Res. 88, 10667-10678.

Roberts J.M., Hahn C.J., Fehsenfeld F.C., Warnock J.M., Albritton D.L. and Sievers R.E. (1985) Monoterpene hydrocarbons in the nighttime troposphere. Environ. Sci. Technol. 19, 364-369. 